Cad.Est.Ling., Campinas, 47(1) e (2):49-59, 2005

\title{
PASSADO, PRESENTE E QUESTÕES PARA O FUTURO NO ESTUDO DA ARGUMENTAÇÃO NA FALA DA CRIANÇA
}

\author{
MARIA FAUSTA PEREIRA DE CASTRO \\ (IEL, Universidade Estadual de CAMPInAS \\ Grupo de Pesquisa em Aquisição da Linguagem)
}

\begin{abstract}
This work deals with argument construction in child speech, starting by submitting to revision some of the questions handled by the author all along her research on that subject. In order to stress the theoretical moves which have been made, two main questions were brought into discussion. Namely, the presence of arguments from the adult speech in the child utterances and the effect of argumentative utterances of the type $\mathrm{x}$ connective $\mathrm{y}$ in restraining deviation in dialogue, thus assuring both meaning and unity. However, the cohesive force of arguments is not free from being disrupted by dispersion and unpredictability. The unfolding of this theoretical perspective opens the way to a hypothesis both on language functioning and on the subjectivity who is constituded in it.
\end{abstract}

Para participar desta mesa-redonda, cujo foco é a trajetória de cada um dos membros fundadores do Projeto de Aquisição de Linguagem ${ }^{1}$, escolhi o mesmo tema da minha tese de doutorado, isto é, a argumentação na fala da criança. Por coincidência, mas não tanto por acaso, este é também o tema de que tenho me ocupado há mais ou menos dois anos, como parte de um projeto de pesquisa vinculado ao $\mathrm{CNPq}^{2}$.

Estas relações justificam de algum modo o título deste artigo, que corre o risco de sugerir ao leitor uma grande revisão bibliográfica e diretrizes para pesquisas futuras. Não se trata disso porém. O que trago aqui é apenas um passado que se faz presente nas indagações teóricas de hoje, o que permite a formulação de novas questões.

A reintrodução do tema, como não poderia deixar de ser, veio marcada por resignificações teóricas e deslocamentos. Não é portanto apenas o tempo como cronologia que está entre os dois estudos, o que marcaria o primeiro como definitivamente ultrapassado, mas os deslocamentos que, ao contrário do fator temporal, ressaltam a pertinência da questão e a resignificam teoricamente.

\footnotetext{
${ }^{1}$ De agora em diante, "O Projeto".

${ }^{2}$ Bolsa de Produtividade em pesquisa, processo no 309105/2003-0.
} 


\section{O PASSADO: O ESTUdO dA ARGUMENTAÇÃO E OS OBJETIVOS DO PROJETO}

Na sua fundação, o Projeto se propunha a estudar as relações entre desenvolvimento lingüístico, desenvolvimento cognitivo e comunicativo ${ }^{3}$, seguindo assim a linha do que se fazia no mundo naquele momento. Dentro desta perspectiva, minha função inicial, pela formação em psicologia, seria a de responder pela tarefa de enfrentar o problema das relações entre cognição e linguagem, assim como da hipótese de que o desenvolvimento lingüístico seria precedido e determinado pelo desenvolvimento cognitivo. Era sobretudo a relação da psicolingüística com a teoria piagetiana que sustentava esta indagação ${ }^{4}$.

Em artigo recente, de Lemos (2002) reconhece que duas barreiras impediram o "distanciamento do lingüístico" que o debate teórico poderia acarretar. A primeira foi o fato de "a questão que inspirou o Projeto - a fala da criança e o quantum de lingüístico que se podia e se devia atribuir a ela - ter-se mantido como eixo da interpretação e do desejo de teorização" e a segunda, o fato de as pesquisadoras que nele se engajaram serem lingüistas voltadas para os problemas lingüísticos, ou o meu caso, que chegando da psicologia, estava realmente interessada em linguagem (De Lemos, 2002: 45)

A entrada na questão da argumentação nasceu como um estudo sobre as relações de causa e efeito nos enunciados complexos presentes na fala de 2 crianças, que foram por mim acompanhadas entre 2;6 e 5;0 anos a primeira, e entre 3;2 e 5;0 a segunda.

Se por um lado o tema "relações de causa e efeito" remete à teoria piagetiana, por outro, sua abrangência teve como primeiro efeito a expansão do tipo de enunciados a estudar. Além dos enunciados complexos com porquê foram também estudadas inferências do tipo se p então q, se p, q perguntas com por que?, e as respostas das crianças a este tipo de perguntas.

O passo seguinte, ou melhor, concomitante à constituição do próprio corpus, foi dado em direção à linguíistica, às questões sintático-semânticas que sustentam o debate sobre a diferença entre "razão e causa", entre "explicativas e causais". Assim se constitui a possibilidade do recorte de um corpus, a partir da hipótese de que as justificativas, inferências, perguntas e resposta a questões com por que? podem ou não manifestar relações de causa e efeito; antes, o que estes enunciados presentes na fala da criança mostravam eram marcas de argumentatividade, que me cabia explicar.

${ }^{3} \mathrm{O}$ título do Projeto financiado pela FAPESP foi: "Relações entre desenvolvimento cognitivo e desenvolvimento pré-lingüístico e lingüístico em crianças brasileiras".

${ }^{4}$ Apesar da inserção do Projeto neste quadro teórico, já no artigo "Algumas observações sobre a utilização do modelo piagetiano em recentes estudos de aquisição da linguagem" (1978), em que participo como coautora com Cláudia Lemos, advertíamos sobre os riscos teóricos de se tomar o modelo piagetiano nos estudos em aquisição de linguagem.

Recentemente retomei a questão da psicologia nas teorias em aquisição de linguagem no artigo "A psicologia na história das idéias em aquisição de linguagem”, apresentado na $9^{\text {a }}$ Conferência Internacional de História das Ciências da Linguagem, São Paulo, 2002. Este trabalho ainda está inédito.

${ }^{5}$ No decorrer deste artigo retomo a questão da hipótese de L'argumentation dans la langue de Ducrot e Anscombre e Ducrot e Carrell. 
Cadernos de Estudos Lingüísticos 47(1) e (2) - Jan./Dez. 2005

Os trabalhos de Ducrot $(1972 ; 1981)$ e de Vogt $(1977 ; 1978)$ deram-me os elementos para o reconhecimento de que a própria língua traz marcas de argumentatividade 5 . Por outro lado, a partir da discussão sobre razão e causa, presente no debate da lingüística (ver, por ex., Rutherford, 1970; Kac, 1972; Lyons, 1977, entre outros autores) e entre os gramáticos (Said Ali,1964; Bechara, 1964), foi possível fazer um deslocamento teórico sustentado pela noção de ato de fala, explícita ou implicitamente presente na discussão. Dois excertos, entre outras passagens do meu trabalho (1985/1996), apontam para a entrada da teoria dos atos de fala no tratamento do problema da argumentação.

\begin{abstract}
"Mas se a dicotomia entre justificativa "do que se diz" e justificativa "do que se pensa"6 não parece suficientemente clara, pressente-se nesse critério uma intuição que é fundamental, isto é, a separação entre ato de fala e conteúdo proposicional que, muito provavelmente, oferece um terreno mais seguro para o esclarecimento da questão". ( Pereira de Castro, op.cit: 55-56 )

e

"É importante chamar a atenção para o fato de que mesmo em uma abordagem sintática do funcionamento do conectivo porque fica demonstrado que tanto a noção de ato de fala quanto a de operação argumentativa são invocadas na descrição e explicação desse funcionamento. Ou, em outras palavras, que a intersubjetividade se dá como perspectiva estruturante". (Pereira de Castro, op. cit: 56-57. Mantidos os grifos e aspas do texto original)
\end{abstract}

É o encontro destas questões, das soluções locais no debate sobre a argumentação com o problema específico à aquisição de linguagem, que vai dar ao trabalho o impulso teórico que me permite pôr em dúvida a tese piagetiana sobre as relações entre desenvolvimento cognitivo e desenvolvimento lingüístico; tese que considera estes domínios como distintos, o primeiro precedendo e determinando o segundo na aquisição de linguagem. A noção de "processos dialógicos" e a decisão teórico-metodológica de se considerar o diálogo como unidade de análise, formuladas por de Lemos $(1981 ; 1982)$ no quadro dos debates do Projeto, permitiram-me redimensionar a questão da argumentação na fala da criança pela sua relação com a fala do outro ${ }^{7}$. As relações de cunho lingüístico entre os enunciados do adulto e da criança no diálogo, os diferentes modos de incorporação, os efeitos argumentativos destas relações, levam-me, de fato, a interrogar a criança piagetiana.

Entretanto, permanece nesta fase do trabalho sobre a argumentação um ponto de vista de língua como objeto de conhecimento, embora se reconhecesse que este último se construía na e pela linguagem. Assim finalizo minha tese de doutorado: "A história dessa prática [da linguagem] é o percurso para a construção da noção de argumento. Em outras

${ }^{6}$ As duas expressões entre aspas se referem a uma citação de Bechara (op. cit), que antecede este excerto.

${ }^{7}$ É interessante notar que em um artigo recente, Sbisà (2002) afirma que um dos defeitos reconhecidos da teoria dos atos de fala é a sua inabilidade em dar conta dos fenômenos "seqüenciais" (sic) no uso da linguagem. Segundo a autora não há análise de atos de fala na conversação como tal. A atribuição de atos de fala parece estar ligada aos limites da sentença (op. cit.: 71). Nesse sentido, ao tratarmos a argumentação pelo prisma da noção de ato de fala, considerando o diálogo como unidade de análise, tomávamos uma via não canônica na abordagem do problema. Voltarei à questão dos limites da sentença na análise da argumentação na fala da criança. 
palavras, é daquilo que a criança faz argumentando que nasce esta noção" (Pereira de Castro, 1985/1996: 257).

Não se esgotam aqui os limites deste primeiro momento do trabalho sobre a argumentação. Entretanto, assumo uma perspectiva de certo modo redutora, deixando de lado outros aspectos da questão ${ }^{8}$, tantas outras críticas necessárias ${ }^{9}$, para marcar um ponto de passagem, uma inflexão no tratamento da argumentação na aquisição de linguagem.

Dois processos apontados como responsáveis pelas mudanças na fala da criança, no que diz respeito à argumentação, foram foco de reinterpretação recente. É através de uma breve apresentação deles e à luz da minha hipótese atual sobre a questão que poderei passar do passado para o presente e apontar uma questão que se abre para o trabalho futuro.

O primeiro, e sempre atual, é a incorporação de argumentos da fala do adulto pela criança.

Tal perspectiva permitiu-me reconhecer o papel determinante da incorporação de argumentos do adulto pela criança, assim como os efeitos que ela promove, de um lado, no adulto, quando fragmentos ou blocos de seus próprios argumentos retornam como fala da criança. De outro, nas mudanças que se fazem sentir na relação da criança com a língua; pelos efeitos promovidos pela fala do outro e ainda pelos efeitos tanto sintáticos, como o de sentido, que o ato de dizer - ou de argumentar - acarreta. Presente desde as primeiras palavras ou fragmentos, já que ela é a via de entrada da criança na linguagem, a incorporação permite que se reconheça a indeterminação da fala inicial da criança e que se interrogue o estatuto dos primeiros enunciados do tipo $\mathbf{x}$ conectivo y no universo da razão. Partes ou blocos inteiros de argumentos do adulto surgem na fala da criança mas, por outro lado, os deslocamentos, os erros, as contradições, as respostas insólitas, exibem a dependência para com uma logicidade e sistemacidade que são do outro e obrigam a que se indague sobre o estatuto dos argumentos que aparentam correção.

Chamei aqueles argumentos que dão a impressão de que a criança sabe sobre o que está falando de argumentos cristalizados, isto é, incorporações de advertências, justificativas ou inferências do adulto, que promovem efeito de unidade e efeito sobre o outro. Entretanto, concomitantes a eles, argumentos que não mostram - como no caso dos primeiros - a relação com a fala do adulto ou que dela se distanciam pelas contradições, erros ou arranjos insólitos, as desestabilizações do que parecia cristalizado insistiam nos corpora e exigiam explicação.

O segundo processo de mudança na fala da criança aponta para um outro pólo constitutivo da argumentação, para as relações gramaticais e semânticas nos enunciados do tipo $\mathbf{x}$ conectivo $\mathbf{y}$. A partir da perspectiva da relação da criança com a linguagem, chamei este processo de "exercícios sobre estruturas" ou "pólo do enunciado". O trabalho

\footnotetext{
${ }^{8}$ Deixo de lado, por exemplo, a ampla discussão realizada em torno do vínculo entre "negação e argumentação".

${ }^{9}$ O que chamei de "negociação" entre os interlocutores - adulto e criança - seria uma, entre tantas questões a debater. De um modo implícito o deslocamento sofrido pela noção de "intersubjetividade" simplesmente abole qualquer pertinência do conceito. Mas o importante é frisar que não cabem aqui críticas locais, apenas o acompanhamento da questão da argumentação e suas hipóteses centrais.
} 
Cadernos de Estudos Lingüísticos 47(1) e (2) - Jan./Dez. 2005

de Ducrot e Vogt (1980) sobre a negação (e afirmação) argumentativa, em que os autores afirmam que o sentido de um enunciado não resulta de condições de verdade, mas das continuações de que o enunciado é suscetível num encadeamento argumentativo, forneceu a base para parte de minha reflexão (1985/1996, entre outros ).

Embora hoje reconheça a impropriedade da expressão "exercício sobre estruturas", que remete à função de síntese do sujeito da psicologia, à depreensão pela criança da estrutura do enunciado, é possível dizer que ela me valeu como instrumento conceitual para o tratamento das questões relativas ao estatuto lingüístico dos enunciados argumentativos: os conectivos abrem lugares a serem preenchidos por elementos que se atualizam na tensão entre o que se abre como espaço vazio, e portanto de liberdade, e o que se fecha pelas restrições impostas pelo conectivo. O encadeamento de elementos da língua ${ }^{10}$ não é, contudo, suficiente para dar conta do funcionamento lingüístico. Ao movimento de articulação corresponde aquele de retroarticulação (Milner, 1989) e o papel do conectivo, como bem observa Bernardes, seria o de um "comando retroarticulatório" na medida em que é o "motor" de uma reconfiguração gramatical da cadeia (2002: 45-46). É portanto pelos movimentos de articulação e retroação, ou retroarticulação (Milner, op. cit.), que os enunciados ganham tanto unidade gramatical e semântica quanto efeitos argumentativos.

Estas questões, brevemente apresentadas, correspondem à minha leitura, hoje, de um primeiro momento do trabalho sobre a argumentação na aquisição de linguagem. Cabe agora perguntar: qual o destino do conjunto de hipóteses e problemas debatidos? As elaborações do presente constituem um passo na retomada destas questões e na abertura de novas indagações.

\section{O PRESENTE: TRABALHOS RECENTES E QUESTÕES PARA O FUTURO}

É possível dizer que as questões do presente retomam tanto a relação da fala da criança com a fala do adulto, quanto os fatos de língua na argumentação, mencionados no item acima. Entretanto caberia igualmente observar que minha posição atual em muito difere daquela que colocava em relação os processos intersubjetivos e linguagem. Tanto a relação entre a fala do adulto e a fala criança foi revista, quanto a hipótese sobre o funcionamento dos enunciados argumentativos é retomada pela discussão sobre as perspectivas que se abrem para o estudo sobre a argumentação na aquisição de linguagem com a teoria da argumentação na língua, reformulada por Ducrot e colaboradores (1983; 1999; 2000-2001, entre outros).

Não farei aqui uma reflexão sobre o percurso desta mudança porque isso implicaria passar pela relação do meu trabalho com o que publicou de Lemos em aquisição de linguagem (2002, para citar apenas um artigo de revisão do seu próprio trabalho), com a reflexão milneriana sobre a lingüística como ciência $(1978 ; 1989)$, e a releitura de Saussure

${ }^{10}$ Expressão utilizada por Milner (1989). 
CASTRO - Passado, presente e questões para o

(1968; 2002). Trago apenas três artigos (Pereira de Castro 2001; 2002; 2004) em que são debatidas questões sobre a argumentação na aquisição de linguagem.

Em fevereiro de 2002, ao participar da mesa-redonda da ALFAL", "Aquisição de linguagem: entre fatos de língua e discurso", retomei o tema da argumentação pelo foco da análise entre certos fatos textuais-discursivos e fatos de língua. No artigo "A argumentação na fala da criança: entre fatos de língua e de discurso" (2001), meu ponto de partida foi a consideração de que a lingüística, a partir da noção de frase/sentença, exclui de muitas de suas análises enunciados que envolvem duas ou mais sentenças ligadas por conectivos. Este é o caso, por exemplo, da gramática gerativa, que exclui enunciados como justificativas do tipo x porque y. De fato, incluí-los implicaria deslocar a questão do âmbito da frase para a análise da relação entre certos fatos textuais-discursivos e fatos de língua.

A argumentação é sempre uma fala dirigida a um outro e o valor argumentativo desse tipo de enunciado se constitui no âmbito do texto, aqui compreendido também como diálogo. Como observou de Lemos (1995), no diálogo atuam as restrições habitualmente atribuídas aos textos. Como estes, o diálogo organiza uma unidade, mas que considerada pelo ponto de vista da inclusão do falante, não exclui a ruptura, a dispersão, a não coesão. Nesse sentido "enunciado" e "frase e sentença" não se equivalem: o primeiro introduz o falante na sua relação com a língua e a frase constitui o limite para a análise do ponto de vista da lingüística.

O três artigos em questão (op.cit), ao tratarem da língua na fala da criança, tomam como efeito do funcionamento lingüístico da argumentação a contenção da deriva no diálogo, garantindo sentido e unidade. Mas, esta força coesiva da argumentação não deixa de ser afetada pela dispersão ou imprevisibilidade, pela ruptura ou fragmentação ${ }^{12}$. Os desdobramentos desta perspectiva abrem lugar para uma hipótese sobre o funcionamento da língua e sobre um sujeito que nela se constitui ${ }^{13}$.

A hipótese estruturalista de Ducrot e colaboradores - Ducrot e Anscombre (1983); Ducrot (1999) e Carel e Ducrot (2000-2001) - sobre a argumentation dans la langue, retomada a partir de um ponto de vista da aquisição de linguagem, sem adesão à totalidade daquela hipótese, sobretudo na tese desenvolvida sobre a teoria do blocos semânticos (Carel-Ducrot, op.cit), oferece os elementos essenciais para que se pense a argumentação como um funcionamento que resiste à dispersão, dirige o diálogo ou o texto.

Para os autores o sentido de uma entidade lingüística não é constituído nem pelas coisas ou fatos denotados, "nem pelos pensamentos ou crenças que ela exprime, mas por

${ }^{11}$ XIII Congresso da ALFAL (San José de Costa Rica). Note-se que embora o evento tenha ocorrido em 2002, o volume a ele dedicado foi publicado com a data de 2001. Por isso a discrepância que se nota entre a data do evento e a da publicação correspondente.

${ }^{12}$ Em "Ainda a negação: questões sobre a interpretação" (1995), discuto, entre outras questões, o papel dos processos metafóricos e metonímicos (De Lemos, 1992, entre outros) na desestabilização dos enunciados cristalizados. Não tratarei entretanto deste texto aqui. Limito-me, como já mencionei acima, a tratar de três trabalhos mais atuais $(2001 ; 2002$ e 2004).

${ }^{13}$ Cada um dos trabalhos citados traz episódios da fala da criança no diálogo com o adulto em que se analisam tanto os fenômenos de encadeamento 'que fazem texto', quanto aqueles que sofrem a ação da ruptura e da fragmentação. 
Cadernos de Estudos Lingüísticos 47(1) e (2) - Jan./Dez. 2005

certos encadeamentos discursivos que ela evoca", isto é, as argumentações. Para eles uma argumentação é um discurso ou um encadeamento do tipo $\mathbf{x}$ conectivo y (CarelDucrot 2000-2001).

São várias as implicações desta tese sobre a argumentação na língua ${ }^{14}$, mas quero aqui chamar a atenção para duas delas: a rejeição de qualquer hipótese que explique a argumentação no nível do pensamento ou das crenças, fora da linguagem, a rigor, abre a possibilidade para o fato de que pode haver fala sem conhecimento, mas que ainda assim promove efeitos de referencialidade, de sentido, de coesão ou unidade e efeitos sobre o outro. Este é o caso dos chamados argumentos cristalizados mencionados acima e cujo funcionamento no diálogo dá a ver estes mesmos efeitos. Em segundo lugar, para os autores o sentido se dá a posteriori: por retroação ou retroarticulação e, de tal forma, que pelos seus encadeamentos a possibilidade de uma nova extensão do enunciado transforma retroativamente o que foi dito antes. É importante notar que em artigo assinado com outros colegas (Bruxelles, S; Ducrot, O. e Raccah, P-Y, 1995) Ducrot reconhece o fenômeno da retroação em funcionamento na argumentação. Os autores falam apenas da "retroação semântica", mas não deixam de relacionar esta noção à linearidade da sentença ao dizer que a primeira depende da segunda e que o efeito argumentativo de um enunciado ${ }^{15}$ é em parte "determinado pela própria sentença" (op. cit.:107).

A tese da argumentation dans la langue leva o autor, a um certo momento e por fidelidade declarada ao estruturalismo, a romper com sua antiga filiação à tradição da retórica. Ele próprio diz que sua originalidade inicialmente se resumia em relacionar à natureza da linguagem a necessidade de substituir a argumentação à demonstração, pensando encontrar nas palavras da língua a marca do caráter fundamentalmente retórico ou "argumentativo" do discurso. A argumentação seria nesta perspectiva uma forma degradada de demonstração. Entretanto, o autor é levado a uma ruptura mais radical.

"Mas parece que somos levados a dizer muito mais. Não somente as palavras não permitem a demonstração, como tampouco permitem esta forma degradada da demonstração que seria a argumentação. Esta também é tão somente um sonho do discurso, e nossa teoria deveria antes se chamar "teoria da não-argumentação", (Ducrot, 1999: 1)

A filiação declarada de Ducrot ao estruturalismo, e a Saussure (s.d.) em particular, aponta para a necessidade de se identificarem neste último as razões que justifiquem minha hipótese de um encadeamento argumentativo que resiste à dispersão, que funciona como contraponto à deriva, mas que também é suscetível à imprevisibilidade, aos furos no encadeamento.

Trajeto que se fez em parte pela passagem por um artigo de Cláudia Lemos (1995), sobre Língua e discurso na teorização sobre aquisição de linguagem.

\footnotetext{
${ }^{14}$ Ver Pereira de Castro 2001 (op.cit.).

${ }^{15}$ Note-se que em Ducrot (1999), ao falar de encadeamento argumentativo, o autor exclui as relações paradigmáticas. Para ele estas mobilizariam noções como "condições de verdade das frases", o que acarretaria uma reflexão do tipo lógico. Está em questão nesta observação a operação de inferência entre frases. Este mesmo artigo também explora a questão da retroação semântica: "Minha tese é que o sentido mesmo de A é determinado pelo de C, e reciprocamente" (op. cit.: 7).
} 
Segundo esta autora as relações entre encadeamento e imprevisibilidade estão presentes na lingüística desde a sua fundação com Saussure. Ao excluir da língua a fala como esfera individual o autor não impede o retorno desta como o espaço do imprevisto, onde se pode exercer a liberdade de combinações. É importante notar que para ela este retorno se dá justamente quando Saussure se volta para o "encadeamento", que define o sintagma e seria já um espaço "livre para o individual" (de Lemos, op. cit.:12). Mas um espaço de liberdade também se abre no eixo associativo e como bem observa de Lemos, se há imprevisibilidade no eixo do discurso, na cadeia da fala, mas igualmente nas relações associativas, na memória fora do discurso, por que então manter a dicotomia entre língua e fala? A autora mostra que são os efeitos restritivos que servem a Saussure para distinguir entre o sintagma e os grupos associativos: as restrições que se aplicam ao primeiro não se aplicam a estes últimos. O domínio da fala não estaria mais no eixo do sintagma. Se é possível falar em "liberdade" de escolha, é no eixo associativo que ela se "oferece ao sintagma" (op.cit:14).

Restaria ainda uma questão: o que a língua com suas restrições deixa como espaço para o exercício da liberdade? Para de Lemos, o imprevisível - constelação, sistema latente - pode atuar em qualquer ponto da cadeia; "a estratificação da cadeia em palavras ou frases corre sempre o risco de se desfazer e de se refazer" (op. cit.:15).

Esta questão é também tematizada por Milner (1978) no capítulo "De la langue" do livro L'amour de la langue. Ao tratar de um ponto de subjetivação que pode operar em qualquer ponto da cadeia, diz o autor: "O ponto de subjetivação é sempre um entre outros, e tão logo circunscrita a cadeia em que ele se distingue, mil outras cadeias análogas surgem (...)" (op. cit.:104. Minha tradução). É portanto a partir da posição subjetiva do falante que a relação entre uma cadeia e as "mil outras" que lhe são associáveis pode ser pensada; um leque de possibilidades que vão no sentido contrário ao da restrição imposta pelos enunciados argumentativos.

No mesmo capítulo mencionado Milner retoma alguns pontos relativos à relação do falante com o outro de um modo tão original que permite, a meu ver, um avanço na leitura da teoria ducrotiana. Leitura particular, que interpõe entre a reflexão de dois autores tão distintos a especificidade do objeto, a fala da criança, que dá grande visibilidade à tensão entre a força coesiva da argumentação pelo funcionamento lingǘstico e a imprevisibilidade que se introduz pela irrupção de um "ponto de subjetivação". Trata-se de uma nova articulação do problema da interação, que se constitui tanto como uma questão do presente, como uma tarefa para o futuro deste meu trajeto no estudo da argumentação na fala da criança ${ }^{16}$. Ler Ducrot com Milner implica a meu ver reconhecer a necessidade de se discutir na teoria do primeiro autor a questão da subjetivação ${ }^{17}$.

16 Além dos artigos que venho mencionando ao longo deste texto $(2001 ; 2002 ; 2004)$, em outubro de 2005 retomarei a questão da argumentação no XIV Congresso da ALFAL com o artigo "A argumentação na fala da criança: a singularidade e a incorporação de argumentos".

${ }^{17}$ Esta discussão deverá passar necessariamente pela sua teoria polifônica da enunciação, quando o autor toma esta última como um conceito que não encerra em si "desde o início, a noção de sujeito falante". (Ducrot, 1987: 169). 
Cadernos de Estudos Lingüísticos 47(1) e (2) - Jan./Dez. 2005

Ao se deter na discussão sobre o modelo da comunicação Milner afirma que "dois seres falantes são necessariamente e realmente distintos e, sob nenhum ponto de vista, a diferença entre eles pode se aplainada" (op. cit: 101). Tal modelo, em que toda lingüística se apoiaria a certo momento, funcionaria como uma máscara que aplica à relação de conjunção impossível o princípio da simetria e do indiscernível, preenchendo assim a nãoconjunção pela igualdade e simetria entre os termos.

Tomando a disparidade do diálogo adulto-criança como paradigma da nãoconjunção, pela assimetria entre seus pares, minha hipótese é a de que a argumentação, por suas propriedades de contenção da deriva e de fala dirigida a um outro, promove no diálogo efeitos de conversão da disparidade em nivelamento da diferença, velando momentaneamente a assimetria que o caracteriza.

Chamo atenção do leitor para o fato de que não se trata mais, como no passado, da intersubjetividade no diálogo, hipótese por que se toma uma relação entre semelhantes, mas de uma disparidade subjetiva que a argumentação, pelos seus encadeamentos, sutura. O diálogo se oferece assim aos olhos do investigador como uma relação de conjunção sobre a qual tão freqüentemente se aplica a máscara do modelo da comunicação.

Milner vê no próprio funcionamento da língua e na linguagem um funcionamento que se abre para esta possibilidade:

[...] elas [a língua e a linguagem] suprem o hiato, convertem magicamente os efeitos deste em um igual número de marcas contrárias: a topologia da não-conjunção torna-se espaço da comunicação, a heterogeneidade dos seres falantes conta-se como homogeneidade dos parceiros da troca, a migalha de locução se faz mensagem (Milner, op.cit.: 102).

Para Milner a não-conjunção se mantém na mis-en-scène, mas é sempre possível denegá-la porque tanto a linguagem, "como conceito, e a língua como suporte de um real", não são nada mais do que esta suplência.

É tempo de concluir, ou melhor, de reconhecer duas vertentes para o trabalho futuro: de um lado, a questão aberta pelos efeitos de encadeamento dos enunciados argumentativos, que convertem a disparidade constitutiva do diálogo em nivelamento da diferença, velando momentaneamente a assimetria que o caracteriza. Efeitos da língua e do próprio conceito de linguagem, o que pode levar o investigador à adoção da máscara da comunicação (Milner,1978) ${ }^{18}$.É um novo "impasse metodológico" que se delineia, retomando as palavras de Carvalho (2004, entre outros $)^{19}$, que tem se dedicado ao efeito de estranhamento que a singularidade fala da criança promove no investigador .

Por outro lado, é pela irrupção de um ponto de subjetivação, como se viu aqui na passagem pelos trabalhos de Lemos (1995) e Milner (op.cit.), que a estratificação da cadeia corre o risco de se desfazer, dando a ver ao fundo da mis-en-scène o espaço da nãoconjunção.

18 Esta questão foi em parte discutida no meu trabalho de 2004.

19 A autora parte da concepção de estranhamento formulada por Guimarães de Lemos (2002). A discussão sobre a possibilidade de relação entre a questão do nivelamento da diferença e estes trabalhos ainda está por vir. 
CASTRO - Passado, presente e questões para o

Este reconhecimento aponta para uma nova etapa no trabalho sobre a argumentação na fala da criança, isto é, para este instante de quebra, de um funcionamento singular que dá a ver a imprevisibilidade no encadeamento e que afeta a ilusão argumentativa, o sonho do discurso de que fala Ducrot. O tema tem sido tratado no meu trabalho de um modo pontual, em função da análise de certos episódios da fala da criança, mas ainda não recebeu a teorização que o problema requer.

Nossa hipótese é a de que estes casos tornam evidente a dissimetria entre a fala da criança e a do adulto; mostram que a criança não escuta a diferença entre seus argumentos e os do seu interlocutor, o que revelaria mais sobre um fenômeno de subjetivação do que sobre a língua.

As duas vertentes de trabalho mencionadas requerem uma reflexão sobre o sujeito do enunciado e o da enunciação, assim como a retomada crítica do conceito de enunciação em Ducrot.

\section{$\overline{\text { REFERÊNCIAS }}$}

ANSCOMBRE J.C. \& DUCROT, O. (1983). L'Argumentation dans la langue. Bruxelas: Mardaga.

BECHARA, E. (1964). Gramática Secundária e Gramática Histórica da Língua. São Paulo: Companhia Editora Nacional.

BERNARDES, A. C. (2002). "Pontuando alguns intervalos da Pontuação". Tese de doutorado, IEL/UNICAMP. Inédita.

BRUXELLES, S.; DUCROT, O. \& RACCAH, P-Y (1995). Argumentation and the Lexical Topical Fields. Journal of Pragmatics, 24 (1/2), pp. 99-114.

CARVALHO, G.M. (2004). "A singularidade em aquisição de linguagem: um impasse metodológico". Letras de Hoje, ${ }^{\circ}$ 137, pp. 27-36.

DE LEMOS, C.T. (1981). Interactional Processes and Child construction of language In: DEUTSCH, W. (org.) The Child's Construction of Language. Londres: Academic Press. pp. 57-76.

. (1982). Sobre Aquisição da Linguagem e seu Dilema (Pecado) Original. Boletim da ABRALIN, p. $97-$ 126.

(2002). "Das Vicissitudes da Fala da Criança e de sua Investigação". Cadernos de Estudos Lingüísticos $n^{\circ} 42$, pp. 41-69.

CARELL, M. \& DUCROT, O. (2000-2001). "Présentation Générale de la Théorie des Blocs Sémantiques". Seminário oferecido pelos autores no Instituto de Estudos da Linguagem/IEL/UNICAMP. Campinas, SP: 11 de setembro de 2001.

DUCROT, O. (1999). Os Topoi na "Teoria da Argumentação na Língua. Revista Brasileira de Letras, ano 1, $\mathrm{n}^{\circ} 1, \mathrm{p} .1-11$.

(1981). Provar e Dizer. São Paulo: Global Editorial.

(1987). O Dizer e o Dito. Campinas: Pontes.

(1972). Dire et ne pas Dire. Paris: Hermann.

LEMOS, M.T.G. (2002). A Língua que me Falta. Uma análise dos estudos em aquisição de linguagem. Campinas: Mercado de Letras. 
KAC, M.B. (1972). Clauses of Saying and Interpretation of because. Language, 48,3, pp. 626-632.

LYONS, J. (1977). Semantics. V. 2, Cambridge: Cambridge University Press.

MILNER, J.C. (1989). Introduction à une Science du Langage. Paris: Seuil. . (1978). L'amour de la Langue. Paris: Seuil.

PEREIRA DE CASTRO, M.F. (2004). “A Argumentação na Impossível simetria do diálogo: a aquisição de linguagem. Letras de Hoje, v. 39, $\mathrm{n}^{\circ}$ 3. pp. 37-46.

. (2002). Sobre a fala da Criança no Universo da Razão: da Argumentação. Actas del Congreso Internacional La argumentación. Universidad de Buenos Aires. Mídia Eletrônica - CD-ROM.

. (2001). A argumentação na fala da criança: entre fatos de língua e de discurso. Lingüística, v. 13, pp. 61-80.

(1985/1996). Aprendendo a argumentar. Um momento na construção da linguagem. Campinas: Ed. Unicamp, 1996.

RUTHEFORD, W.E. (1970). Some Observations Concerning Subordinate Clauses in English. Language, 46, pp. 97-115.

SBISÀ, M. (2002). Cognition and narrativity in speech act sequences. In: FETZER, A. \& MEIERKORD, C. (Org.) Rethinking Sequentiality. Amsterdam: John Benjamins Publishing Company.

VOGT, C. (1977). O Intervalo semântico: contribuição para uma Teoria Semântica Argumentativa. São Paulo: Ática.

. (1978). Indicações para uma Análise Semântica Argumentativa das Conjunções porque, pois e já que. Cadernos de Estudos Lingüísticos, $\mathrm{n}^{\circ} 1$, pp. 35-50. 